\title{
FATORES DETERMINANTES DE INSERÇÃO NAS CADEIAS GLOBAIS DE VALOR: UMA ANÁLISE DA PARTICIPAÇÃO DA INDÚSTRIA MINERAL
}

\author{
Ludmila Martins Floris ${ }^{1}$, Cristina Lélis Leal Calegário, Ednilson Sebastião Ávila, Rafaela Maiara Caetano \\ Universidade Federal de Lavras - UFLA, Minas Gerais, MG (Brasil)
}

\section{DETALHES DO ARTIGO}

\section{Histórico do Artigo:}

Recebido: 10 de Dezembro de 2019

Aceito: 30 de Junho de 2020

Disponível online: 01 de Agosto de 2020

Sistema de revisão "Double blind review"

\section{Editor Científico}

Ilan Avrichir

\section{Palavras-chaves:}

Cadeias Globais de Valor

Participação

Indústria Mineral

Dados em Painel

Modelo de Efeito Fixo

\begin{abstract}
RESUMO
Objetivo: Investigar os fatores que contribuem para a participação da indústria mineral nas cadeias globais de valor (CGVs) dos países que serão analisados.

Método: De cunho explicativo e abordagem quantitativa, este estudo utilizou como técnica estatística a regressão múltipla por meio do Modelo de Efeito Fixo. A estrutura dos dados i é em painel, referente a 62 países, e corresponde ao referente a sessenta e dois países para o período de 2001 a 2015.

Principais resultados: Os resultados apontam que $77 \%$ dos países em desenvolvimento possuem baixa participação de suas respectivas indústrias minerais nas CGVs em relação à média apresentada dos países da amostra. Além disso, o resultado do modelo sugere que a abertura comercial e a qualificação da mão de obra são fundamentais para elevar a participação desta indústria nas CGVs. Relevância/originalidade: A indústria mineral é estratégica do ponto de vista econômico para muitos países e além disso, fornece insumos essenciais para a cadeia produtiva de grande parte dos bens utilizados pela sociedade moderna. Apesar disso, são poucos os estudos que analisam esta indústria sob a lente teórica das CGVs.

Contribuições teóricas/metodológicas: Este estudo busca expandir a literatura CGV ao trazer evidências de quais fatores contribuem para a participação da indústria mineral nestas cadeias.

Contribuições sociais / para a gestão (opcional): São apresentados possíveis caminhos que podem melhorar a participação dos países que possuem a indústria mineral pouco integrada.
\end{abstract}

\section{INTRODUÇÃO}

As cadeias de valor globais (CGVs) são consideradas um novo paradigma produtivo, e a sua análise vem despertando interesse em função das grandes mudanças ocorridas no comércio internacional. Os processos de produção passaram a se tornar dispersos mas ao mesmo tempo conectados e propiciando vantagens competitivas para muitos países (Smith, 2015; Tinta, 2017). Assim, muitas nações vêm buscando meios de melhorarem sua participação nas CGVs, pois muitos são muitos os benefícios da participação nestas cadeias (Gereffi, 2014, 2018; Pahl \& Timmer, 2019).

Dentre os diversos conceitos relacionados a participação nas CGVs, um dos mais tradicionais, considera a origem do valor agregado incorporado nas exportações de um país (Greenville \& Kawasaki, 2018; Hummels et al., 2001). Em busca de promover e/ou melhorar esta participação, alguns estudos avaliaram quais seriam os fatores determinantes que promoveriam esta integração a nível regional, como foi o caso dos estados membros da União Europeia (Kersan-Škabić, 2019) e no caso de países específicos como na China (Wang et al., 2019), no Zimbábue (Masunda \& Mupaso, 2019) e outros países africanos (Tinta, 2017).

Apesar destas contribuições, nota- se uma escassez de estudos que identifiquem e analisem os fatores que possibilitam uma maior participação nas CGVs em uma análise micro, a nível por exemplo, de setores econômicos e indústrias específicas. Trata- se de uma questão relevante e que merece ser investigada, uma vez que determinadas indústrias contribuem com uma parcela significativa do desempenho econômico de muitas nações, e por isso, devem ser avaliadas como "peças chaves" na dinâmica CGV. Este é o caso de indústrias 
Fatores Determinantes de Inserção nas Cadeias Globais de Valor: Uma Análise da Participação da Indústria Mineral

pertencentes ao setor extrativista, as quais constituem como fonte de renda principal para muitas economias emergentes. Para se ter uma ideia desta realidade, uma única commodity em trinta e oito países é responsável por mais de $50 \%$ de suas rendas (UNCTAD, 2016).

Neste cenário, destaca- se de modo especial, a indústria mineral, que é uma fornecedora de insumos primários essenciais para as CGVs e que tem a demanda por bens primários aumentando consideravelmente ao longo dos anos. A busca por commodities minerais, de forma especial os estratégicos, aumenta cada vez mais em função do crescimento das economias emergentes e da disseminação de novas tecnologias (Fortier et al., 2018; Henckens et al., 2014; Katz \& Pietrobelli, 2018). Apesar disso, a indústria mineral não recebe muita atenção na literatura CGV, apesar dos recursos naturais terem um papel indispensável ao longo destas cadeias (Smith, 2015).

Na literatura CGVs o mais comum é encontrar trabalhos que versam sobre os recursos naturais de uma maneira geral (Piorski \& Xavier, 2018; Smith, 2015), e quando específicos, tratam em sua maioria, de commodities agrícolas (Dolan \& Tewari, 2001; Heery et al., 2016; Heron et al., 2018; Purcell et al., 2018). Outras pesquisas que versam sobre CGVs fornecem um panorama geral de vários setores em conjunto, sendo raros aqueles que se dedicam analisar uma indústria específica. Neste último caso, os poucos estudos identificados que analisaram a indústria mineral na perspectiva CGVs parecem possuir duas vertentes principais: A primeira dedicase a analisar as oportunidades de inovação na indústria mineral (Katz \& Pietrobelli, 2018; Pietrobelli et al., 2018; Stubrin, 2017), e a segunda, dedica- se a avaliar as possibilidades de diversificação produtiva através do desenvolvimento de ligações a partir desta indústria com demais setores econômicos (Bamber et al., 2016; Fessehaie, 2012; Morris \& Fessehaie, 2014; Morris et al., 2012; Piorski \& Xavier, 2018).

Porém, não foram localizados estudos que investigassem o nível de participação da indústria mineral mundial - em especial, dos países em desenvolvimento nas CGVs - e nem sobre quais fatores econômicos são essenciais para promover a integração desta indústria nestas cadeias. Neste aspecto, as evidências empíricas são muito abaixo do esperado. A partir desse cenário, este estudo pretende responder a seguinte questão de pesquisa:
Quais são os fatores determinantes para a participação da indústria mineral nas CGVs dos países que serão analisados? O objetivo é investigar os fatores que contribuem para a participação da indústria mineral nas CGVs dos países da amostra. Nesse aspecto, a análise pela perspectiva das CGVs pode beneficiar significativamente indústrias marginalizadas, suas perspectivas de melhoria e os obstáculos que enfrentam (Tejada et al., 2011).

A novidade deste artigo está, portanto, na extensão de pesquisas existentes que se concentram em sua maioria na discussão sobre os fatores condicionantes para a participação nas CGVs a nível de país e/ou região. Neste estudo, ao contrário, focamos no nível industrial, em uma uma atividade do setor extrativista que fornece insumos essenciais para as cadeias produtivas de grande parte dos bens utilizados pela sociedade moderna. Além disso, incluímos para a análise categorias que são fundamentais na lente teórica CGV, como aspectos macroeconômicos e condições estruturais de um país, e ao mesmo, categorias que abrangem informações específicas sobre a indústria mineral. Esse esforço torna- se importante, uma vez que os determinantes da participação de indústrias nas CGVs ainda são pouco explorados nos estudos empíricos.

A escolha da indústria mineral como objeto de estudo, se deu pela sua importância estratégica para muitas nações, e pela oportunidade de obtenção de novos insights em função de sua especificidade em relação a outras indústrias. Cita- se por exemplo, o fato desta atividade produtiva ser pouco fragmentada, contrastando com outros setores que geralmente são recorrentes nas pesquisas que versam sobre as CGVs, como é o caso do setor manufatureiro.

Como contribuição social, pretendemos apresentar os possíveis caminhos a serem tomados pelos formuladores de políticas públicas que possam melhorar a participação da indústria mineral nas CGVs, em especial, para os países dependentes de commodities minerais, como é o caso do Brasil. Ademais, as lições trazidas também poderão ser úteis para outros tipos de indústrias, como a agrícola e energética, as quais em muitos países, configuram-se como principais atividades econômicas.

Para cumprir o objetivo proposto, utilizamos uma abordagem quantitativa através do método de regressão múltipla por meio do Modelo de Efeito 
Fixo. Os resultados apontaram que $77 \%$ dos países em desenvolvimento possuem baixa participação de suas respectivas indústrias minerais nas CGVs em relação à média apresentada dos países da amostra. Além disso, a estimação do modelo sugere que a abertura comercial e a qualificação da mão de obra são fundamentais para elevar a participação desta indústria nas CGVs. Por outro lado, o impacto da infra- estrutura e a diversificação apresentaram influência negativa nessa relação, enquanto que o investimento estrangeiro direto (IED), a inovação, as importações intermediárias reexportadas e a produção bruta não foram significantes para explicar a variável dependente.

O presente artigo está estruturado, além desta introdução, em sete seções. Na seção 2, é apresentado o referencial teórico que será subdividido em dois eixos: O primeiro tratará da participação nas CGVs e alguns fatores determinantes de melhorias de posicionamento; e o segundo fornecerá um panorama geral da indústria mineral no contexto das CGVs. Na seção 3, é apresentado o desenvolvimento das hipóteses, enquanto na seção 4 discute- se os procedimentos metodológicos que serão aplicados. Em seguida, na seção 5 são mostrados os resultados e na seção 6 têm- se as discussões. Por fim, na seção 7, são apresentadas as principais conclusões do trabalho.

\section{REFERENCIAL TEÓRICO}

A seguir, na subseção 2.1 , será apresentada uma breve descrição sobre o papel e as oportunidades da indústria mineral nas CGVs. Em seguida, na subseção 2.2, será discutido o conceito de participação nestas cadeias, seguido do desenvolvimento das hipóteses que serão testadas neste estudo.

\subsection{A indústria mineral no contexto das CGVs}

O termo "mineração" deriva do latim (mineralis) e refere- se ao processo de extração de minerais a partir da crosta terrestre que possui valor econômico e de utilidade para a sociedade (CNI, 2012). O ciclo da mineração, é composto por seis etapas principais segundo Balasubramanian (2016): (a) Pesquisa Mineral e Exploração: busca por depósitos minerais, (b) Desenvolvimento: preparação da mina para início da lavra, (c) Explotação: operação de lavra, (d) Fechamento de Mina: recuperação da área degrada e término das operações mineiras. A indústria mineral abrange neste caso, todo os processos envolvidos no processo de retirada e beneficiamento dos bens minerais incluindo os minerais metálicos e não metálicos, carvão e água mineral.

Trata- se de uma atividade essencial para a vida moderna cujos produtos são insumos essenciais para uma gama de setores à jusante, em especial, para a indústria de transformação e a manufatureira. Este é o primeiro aspecto que torna a análise desta indústria relevante na lente teórica CGV, de modo específico, pela possibilidade de captura de valor a partir do desenvolvimento de ligações da indústria mineral com outros segmentos econômicos. Isso tornou- se um ponto interessante de análise, porque apesar da indústria mineral tradicionalmente ser pouco fragmentada, nos últimos anos observa- se uma tendência de desintegração vertical das grandes mineradoras (Bravo-Ortega \& Muñoz, 2018; Pietrobelli et al., 2018; Stubrin, 2017). Estas empresas passaram a se concentrar mais em suas capacidades internas e a terceirizarem outros serviços não essenciais.

Esta tendência apresentou oportunidades interessantes de negócios e desenvolvimento para os fornecedores de mineração e, como consequência, para o fortalecimento de ligações à jusante e à montante da indústria mineral (Bravo-Ortega \& Muñoz, 2018). Bamber et al. (2016) por exemplo, analisaram a participação do Peru na CGV de equipamentos e apresentaram evidências de que o desenvolvimento de ligações à montante na mineração ofereceu uma alternativa de desenvolvimento atraente que possibilitou o upgrading de função, para atividades intensivas em capital nas CGvs.

O desenvolvimento de ligações a partir da mineração também foram essenciais para apoiar o sucesso das empresas de fornecimento na cadeia de valor de cobre na Zâmbia (Fessehaie, 2012) e para contribuir com a industrialização da África gerando oportunidades significativas para estes países (Morris \& Fessehaie, 2014; Morris et al., 2012). Isso ocorre basicamente porque estas ligações estimulam a diversificação produtiva para outros tipos de indútrias que agregam maior valor, além de gerar maiores receitas de exportação e ganhos de câmbio. Estes estudos apontam que é possível que a indústria mineral seja o elo para aumentar a participação de muitos países nas CGVs. Para isto no entanto, é preciso que estas indústrias sejam internacionalmente competitivas e efetivamente 
integradas às CGVs (Gereffi et al., 2005; Morris \& Fessehaie, 2014).

Além do estímulo ao desenvolvimento de ligações intersetoriais, o aumento da terceirização e as mudanças globais na indústria mineral (em termos de tecnologias mais eficazes para a pesquisa mineral, explotação da lavra, beneficiamento de minério, pesquisa operacional, e principalmente tecnologias verdes) incentivou em muitos casos a inovação local nos países anfitriões. O surgimento de um grupo de fornecedores altamente inovadores associados às atividades de mineração no Brasil, Chile e Peru (Pietrobelli et al., 2018) e as oportunidades de inovação aproveitadas pelas empresas fornecedoras chilenas que entraram em segmentos dinâmicos da cadeia de valor de cobre (Stubrin, 2017). Estas últimas, personalizaram produtos e serviços considerando as condições produtivas locais específicas e utilizando novas tecnologias como plataforma para desenvolver soluções exclusivas para problemas de mineração não resolvidos.

É nítido que a indústria mineral vem se tornado uma área dinâmica de transformação e inovação tecnológica (Katz \& Pietrobelli, 2018) e por isso a necessidade de se romper com as restrições técnicas do setor, desenvolvendo a indústrias à jusante a fim de se inserirem em etapas mais avançadas nas CGVs (Piorski \& Xavier, 2018). Nesta ótica, torna- se, portanto, importante avaliar quais fatores contribuem para a participação da indústria mineral nas CGVs, e como se dá atualmente esta participação, em especial, dos países em desenvolvimento. Esta análise consiste é um diagnóstico do nível de captura de valor destas nações nas CGVs a partir desta atividade econômica.

2.2 Uma breve visão das abordagens das CGVs e da participação nestas cadeias

A literatura das CGVs pode ser analisada sob diferentes perspectivas que levam em consideração sua diversidade técnica e estratégica. De uma maneira geral, as diferentes correntes buscam explicar como e porque estas cadeias surgem e quais são seus principais efeitos dentro do contexto da

\footnotetext{
2 Gereffi (1994) definiu o conceito de governança no contexto das CGVs como sendo as "relações de autoridade e poder que determinam como os recursos financeiros, materiais e humanos são alocados e fluem dentro de uma cadeia."
}

fragmentação internacional da produção. Neste estudo, serão utilizadas duas abordagens muito empregadas nas pesquisas envolvendo as CGVs.

A primeira delas, denomina- se "GVC approach", a qual foi desenvolvida por acadêmicos da sociologia e da ciência política. Esta corrente possui um caráter fundamentalmente microeconômico de análise e está ligada às empresas multinacionais, estratégias globais e busca investigar as oportunidades de desenvolvimento para as economias emergentes (Gereffi \& Lee, 2016; Humphrey \& Schmitz, 2002; Kaplinsky, 2014; Sturgeon \& Gereffi, 2009).

Esta corrente é constituída a partir de dois pontos de vista opostos: de cima para baixo (top-down) e de baixo para cima (bottom-up) (Gereffi, 2014). O conceito central da visão de cima para baixo é o de "governança ${ }^{2}$ " a qual refere- se ao modo como as CGVs são coordenadas pelos atores destas cadeias. Já na visão de baixo para cima, o principal conceito é "upgrading" que refere- se a possibilidade de avançar ao longo das CGVs em direção a etapas de maior valor agregado, e dessa forma, melhorar a participação nestas cadeias.

Os quatro tipos de upgrading identificados por Humphrey e Schmitz (2002) são tradicionalmente os mais citados nos estudos empíricos nas análises sobre as CGVs. O upgrading de produto promove a melhoria de qualidade de produtos/serviços, enquanto que o upgrading de processo reduz o custo unitário na produção por meio da reorganização do sistema de produção. O upgrading de função por sua vez, consiste na mudança da cobertura de atividades na cadeia de valor para funções de maior valor agregado e já o upgrading de cadeia ocorre a partir do uso do conhecimento funcional em uma cadeia permitindo a expansão para uma função similar encontrada em outra cadeia de um setor industrial diferente.

Enquanto o upgrading de produto e de processo são sobre a melhoria interna de uma firma, o upgrading funcional e de cadeia estão relacionadas à mudança para posições mais altas nas CGVs (Fleury \& Fleury, 2001), e portanto envolve indústrias e setores econômicos. Assim, de uma maneira geral, a

\footnotetext{
3 O upgrading nas CGVs ocorre quando empresas, países ou regiões passam para atividades de maior valor para aumentar os benefícios de participação na produção global (Gereffi, 2005).
} 
abordagem "GVC approach" tem como foco principal investigar as estratégias utilizadas pelos países, indústrias ou empresas para melhorarem sua participação ao longo das CGVs. Neste aspecto, a participação nas CGVs pode ser entendida como sendo uma mudança para níveis mais elevados ao longo destas cadeias, em termos de maior captura de valor.

Já a segunda abordagem, analisa as CGVs em um nível macroeconômico e foi desenvolvida por economistas da área de economia internacional e macroeconomia. Cita- se Hummels et al. (2001) que apresentaram pela primeira vez o conceito participação no comércio verticalmente especializado ${ }^{4}$ e que posteriormente foi refinado por Koopman et al. (2010). A especialização vertical foi a primeira medida empírica de participação nas CGVs, em que Hummels et al. (2001) dedicaram- se na análise do uso de insumos importados na produção de bens a serem exportados. Mais adiante, outros pesquisadores passaram a desenvolver novas métricas e indicadores para mensurarem o comércio internacional (Antràs \& Chor, 2018; Antràs et al., 2012; Caliendo \& Parro, 2015; Fally, 2011; Wang et al., 2017).

Fally (2011) forneceu análises quantitativas sobre o comprimento médio das cadeias de produção, o que propiciou calcular o número de estágios entre a produção e o consumo final. Posteriormente, Antràs et al.(2017) derivaram duas abordagens distintas para medir a produção à montante da indústria. Wang et al. (2017) propuseram uma estrutura para decompor o total de atividades de produção no país e mais recentemente, Antràs \& Chor (2018) estenderam a estrutura de Caliendo e Parro (2015) e forneceram uma interpretação estrutural de todas as entradas de uma tabela de entrada e saída mundial.

Esta evolução nas medidas do comércio internacional só foi possível com o desenvolvimento de novas bases de dados disponibilizadas por organização internacionais Dentre as principais bases, destacam-se a Organization for Economic Cooperation and Development (OECD), United Nations Conference on Trade and Development (UNCTAD) e World Trade Organization (WTO). Os dados baseiamse em sua maioria na decomposição de matrizes de entrada e saída (IOTs) em que é possível mensurar o

\footnotetext{
4 A especialização vertical é definida como o uso de intermediários estrangeiros na produção de produtos exportados (Hummels et al.,2001).
}

comércio de valor agregado, e não bruto como era realizado a décadas atrás.

As bases mais conhecidas são o WIOD (World Input-Output Database) e TiVA (Trade in valueadded), as quais têm em comum o uso das tabelas $\mathrm{ICIO}^{5}$ de países como fonte de dados, e diferem- se basicamente porque a primeira conta com $\mathrm{O}$ comércio para equilibrar as tabelas $\mathrm{ICIO}$, enquanto a segunda utiliza as contas nacionais (Greenville et al., 2017). Já o conjunto de dados UNCTAD-EORA utiliza interpolações de dados no lugar da tabela ICIO. Este banco utiliza tabelas de IOTs nacionais e através de métodos de entropia cruzada interpola os dados para aqueles países que não possuem os dados integrados.

Dessa forma, esta segunda corrente possui um enfoque mais empírico, pois o objetivo em geral, é o desenvolvimento de novas metodologias para medir a fragmentação da produção internacional e o valor adicionado ao longo das etapas nas CGVs. Os estudos citados analisaram vários setores econômicos em conjunto justamente para validar os modelos e indicadores propostos. Apesar deste ter sido o foco destes trabalhos, uma análise multisetorial dificilmente permite explorar com profundidade os nuances de uma indústria específica, como é o objetivo deste estudo. Além disso, questões como quais são os determinantes do posicionamento de um setor e/ou país nas CGVs ainda permanecem sem respostas (Antràs \& Chor, 2018) e, portanto, merecem atenção.

Nesse sentido, um dos desafios que vem sendo investigados em diversas pesquisas sobre a temática das CGVs é compreender de que forma os países e seus setores específicos se encontram inseridos em termos de participação nas CGVs. Isso porque a distribuição de ganhos entre os países nas CGVs ainda é desigual, sobretudo nas economias emergentes (Banga, 2013; Gereffi \& Korzeniewicz, 1994; KersanŠkabić, 2019; Reis \& Almeida, 2014). É neste ponto de confluência que as duas abordagens discutidas anteriormente se complementam e tornam- se relevantes como ferramentas para entender a questão abordada neste estudo. 0 entendimento de quais fatores são relevantes para propiciar uma melhor participação nas CGVs de uma indústria que produz bens de baixo valor agregado e que é

\footnotetext{
${ }^{5}$ As tabelas ICIO (Inter-Country Input-Output) mostram como é a estrutura de entrada e saída dos países envolvidos no comércio internacional.
} 
essencial para a economia de muitos países torna- se relevante.

Neste aspecto, apesar da diversidade de metodologias disponíveis na literatura para mensurar o nível de participação dos países, setores e indústrias nas CGVs, o indicador de participação proposto por Koopman et al. (2010) continua sendo um dos mais utilizados nos trabalhos empíricos (De Backer \& Miroudot, 2014; Kersan-Škabić, 2019; Mikhailov et al.,2017; Reis \& Almeida, 2014; Vlckova \& ThakurWeigold, 2019). O motivo é que ele pode ser aplicado para uma amostra maior, uma vez que não é necessário para o cálculo desta medida, tabelas completas de entrada e saída, as quais em muitos casos, não estão disponíveis para um amplo conjunto de países (Kersan-Škabić, 2019).

Koopman et al (2011) integrou várias medidas sobre especialização vertical e comércio de valor agregado para ajustar o comércio de intermediários e apresentou os índices de posição e participação da GVC para avaliar até que ponto um setor de país está envolvido no mercado global. Desta forma, esta medida fornece uma avaliação abrangente da participação de um país ou setor nas CGVs, tanto como usuário de insumos estrangeiros (participação à montante) ou como fornecedor de bens e serviços intermediários usados nas exportações de outros países (participação à jusante) (Banga, 2013; Sturgeon et al., 2013).

\subsection{DESENVOLVIMENTO DAS HIPÓTESES E MODELO CONCEITUAL}

Alguns fatores vêm sendo relatados como determinantes para a participação nas CGVs. É necessário atender a um certo número de condições para ingressar nas CGV e principalmente, para avançar ao longo destas cadeias e dessa forma participar de etapas com maior valor agregado. A política macroeconômica, as condições estruturais de um país, o comércio exterior e as características da indústria são frequentemente citadas na literatura como sendo os fatores essenciais e prioritários para atingir este objetivo.

No primeiro caso, os fatores políticos são baseados na abordagem institucional e indiretamente estão associados a abertura comercial, adequação de acordos comerciais preferenciais, investimento estrangeiro direto e indicadores de desempenho comercial que podem afetar a competitividade de toda a cadeia de valor (Tinta, 2017). Os países que desejam ingressarem na dinâmica CGVs e se beneficiarem das vantagens do comércio internacional nos moldes desse paradigma produtivo precisam se distanciar de práticas ultrapassadas como elevadas barreiras comerciais para as importações e forte proteção ao mercado doméstico.

As barreiras comerciais inevitavelmente prejudicam os países que as implementam (Sturgeon et al., 2013). Em vez de proteção do mercado doméstico, as políticas protecionistas podem gerar um efeito reverso na participação dos países no comércio internacional. Nesse sentido, a abertura comercial é um fator fundamental para sustentar a competitividade de um país (Ali \& Msadfa, 2016). Este fator influencia o processo de integração nas CGVs e alguns estudos sugerem que os países geralmente mais inseridos são aqueles cujos regimes de comércio são relativamente liberais (Beverelli et al., 2019; De Backer \& Miroudot, 2014; Kummritz et al., 2017).

Além disso, há indícios de uma relação positiva entre investimento estrangeiro direto (IED) e participação nas CGVs. Uma das razões principais, são os ganhos proporcionados pelos transbordamentos tecnológicos que geralmente ocorrem pela relação entre empresas líderes e fornecedores locais do país anfitrião, o que certamente promove o desenvolvimento industrial destas nações. O IED é visto como um canal primário para acessar mercados globais, capital, tecnologia e habilidades (Amendolagine et al., 2017; Staritz et al., 2016) e tudo isso afeta a participação de um país nas CGVs, independentemente de sua estrutura de governança (Kummritz et al., 2017). Com base nestes argumentos postulamos duas hipóteses iniciais para serem testadas neste estudo:

Hipótese 1a. A abertura comercial de um país contribui positivamente para elevar o seu nível de participação nas CGVs, e, por conseguinte, de suas indústrias ${ }^{6}$.

Hipótese 1b. O fluxo de investimento estrangeiro direto de um país contribui positivamente para elevar a participação da indústria mineral nas CGVs.

\footnotetext{
${ }^{6}$ Inclui, portanto, a indústria mineral.
} 
A condição estrutural do país também possui um papel relevante para promover a integração dos países nas CGVs, uma vez que é fundamental uma capacidade de infra- estrutura e logística para promover o fluxo de escoamento e recebimento da produção. Além do mais, da qualificação da mão de obra é indispensável para aumentar a produtividade e promover a inovação necessária para o desenvolvimento de novos bens e serviços que promovam a captura de valor nas CGVs. O aumento da participação nas CGVs, e consequentemente, "a fuga" da armadilha de baixo valor agregado" requer a combinação de vários fatores de sucesso, relacionados principalmente a logística e infraestrutura, inovação e à oferta de mão-de-obra qualificada (Gereffi, 2014; Kummritz et al., 2017; Landesmann \& Stöllinger, 2019).

A capacidade de inserção nas cadeias de valor é dependente das condições de infraestrutura e para a indústria mineral, em específico, estes fatores tomam uma direção ainda mais essencial para uma maior participação nas CGVs. O upgrading na indústria mineral exige uma abordagem mais holística e um foco maior na inovação e na infra-estrutura (Tijaja \& Faisal, 2014). Como trata-se de uma indústria caracterizada pela rigidez locacional, uma vez que os depósitos minerais encontram- se em determinadas localidades os quais, muitas vezes afastados dos centros comerciais, a infra- estrutura e logística tornam- se fundamentais. Além disso, apesar de ser uma indústria de base, cada vez mais tecnologia vem sendo empregada nas etapas da mineração (Katz \& Pietrobelli, 2018) e por isso a necessidade de inovações constantes e mão de obra qualificada. A partir do exposto, apresentamos as seguintes hipóteses relacionadas as condições estruturais:

Hipótese 2a. A infra- estrutura de um país contribui positivamente para elevar o seu nível de participação nas CGVs, e, por conseguinte, de suas indústrias ${ }^{7}$.

Hipótese $2 \mathrm{~b}$. A inovação contribui positivamente para elevar a participação da indústria mineral nas CGVs.

Hipótese 2c. A qualificação da mão de obra contribui positivamente para elevar a participação da indústria mineral nas CGVs.
As características do comércio exterior, tanto em termos de exportação quanto de importação, também dizem muito sobre a participação de um país nas CGVs e constitui um excelente indicador sobre a captura de valor das indústrias nacionais. A intensidade da participação nas CGVs é aproximada pelo uso de insumos importados e pela intensidade das exportações (Andrzej et al., 2019). Dessa forma, a competitividade das exportações continua a ser crucial, mas as exportações de hoje são agora o resultado da participação nas CGVs e, portanto, dependem frequentemente das importações a partir destas redes globais de produção (Milberg, 2013).

Uma das estratégias mais utilizadas por muitas nações é a importação de bens intermediários para serem utilizados na construção de capacidades nas empresas locais para em seguida, serem exportados. A captura de valor nesses moldes, e consequentemente, o aumento da participação nas CGVs, é realizado por meio das importações intermediárias reexportadas (Dean et al., 2008). Diante disso, lançamos a próxima hipótese do estudo:

Hipótese 3a. As importações intermediárias reexportadas da indústria mineral contribuem positivamente para elevar a participação desta indústria nas CGVs.

Outros fatores que podem vir a ter impacto na participação da indústria mineral nas CGVs e que serão investigados neste estudo diz respeito a diversificação da produção (em termos de variedade de bens minerais produzidos pelo país) e a produção bruta de minério. Estas variáveis merecem atenção porque podem indicar como as características de produtivas desta indústria impactam no comércio internacional. Por exemplo, em países em desenvolvimento ricos em recursos minerais, esperase que a taxa de consumo aparente seja inferior ao de países desenvolvidos. Com isso, uma grande produção bruta tende a intensificar as exportações. Nesse sentido, a participação nas CGVs pode ser medida através da variedade da exportação, pois a diversificação oferece mais oportunidades de exportação (Ali \& Msadfa, 2016; Staritz et al., 2016; Tinta, 2017). Este racionício embasa as duas últimas hipóteses:

\footnotetext{
${ }^{7}$ Inclui, portanto, a indústria mineral.
} 
Hipótese 4a. A diversificação produtiva da indústria mineral contribui positivamente para elevar o nível de participação desta indústria nas CGVs.

Hipótese 4b. A produção bruta da indústria mineral contribui negativamente para elevar a participação desta indústria nas CGVs.

Assim, estas hipóteses serão testadas a fim de avaliar quais desses fatores são de fato determinantes da participação da indústria mineral nas CGVs. Esta investigação se faz importante em um contexto onde os governos buscam por estratégias de maior participação junto às CGVs, principalmente, para o setor extrativista (Smith, 2015). Por esta razão, os formuladores de políticas públicas estão procurando mais e melhores evidências que examinem a posição dos países e consequentemente de seus setores industriais dentro das CGVs (De Backer \& Miroudot, 2014). Todas as hipóteses formuladas acima são mostradas na Figura 1:

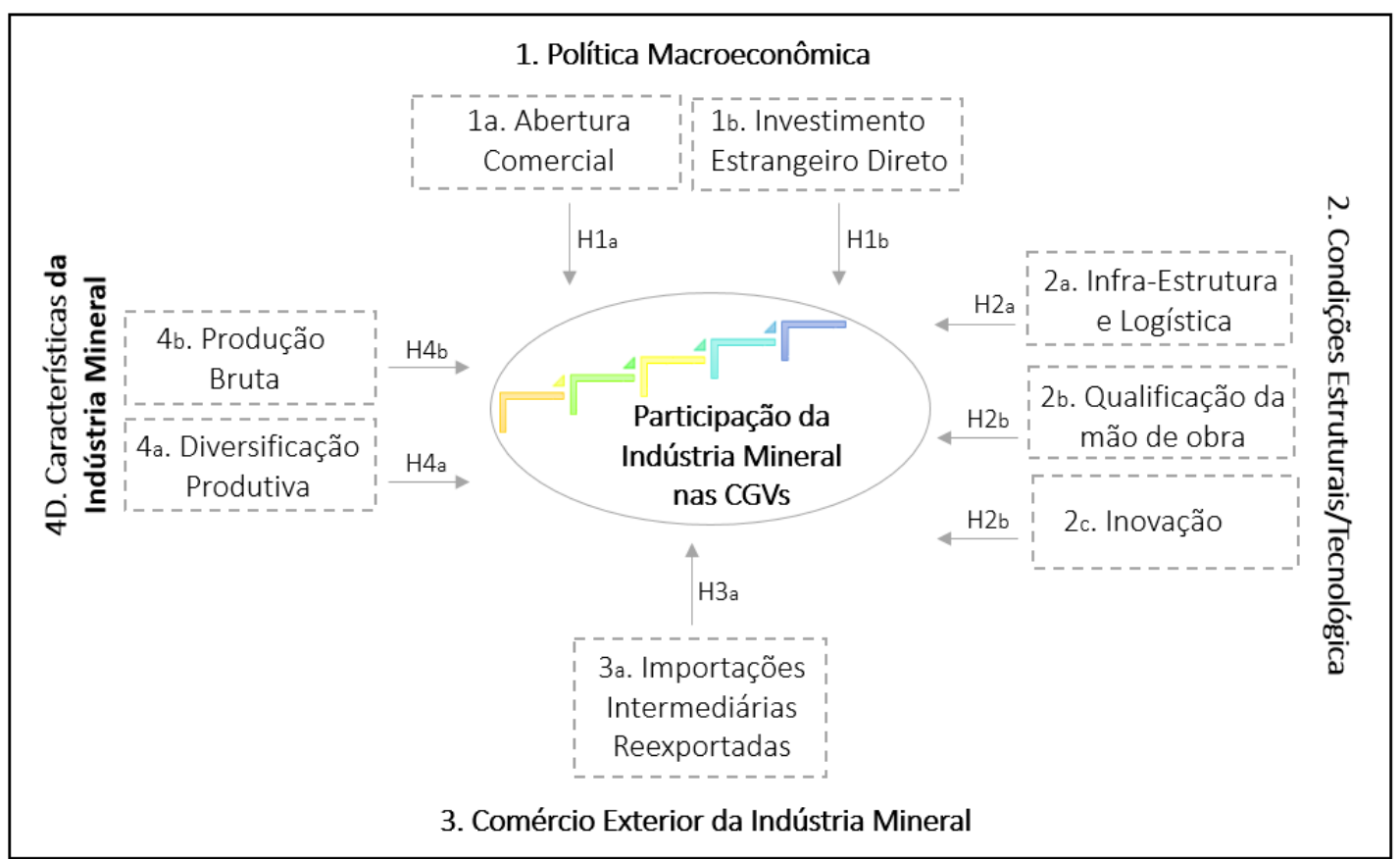

Figura 1: Modelo Conceitual Teórico-Empírico.

A Figura 1 apresenta as oito variáveis independentes e suas respectivas hipóteses que serão testadas sobre a variável dependente participação da indústria mineral nas CGVs. Estas variáveis estão classificadas em quatro categorias: Política Macroeconômica, Condições Estruturais, Comércio Exterior da Indústria Mineral e Características da Indústria Mineral. Os dados das duas primeiras categorias serão a nível país, já que não é possível encontrá-los desagregados a nível industrial para todos os países da amostra.

\section{PROCEDIMENTO METODOLÓGICO}

Este estudo possui natureza aplicada, sua abordagem é quantitativa e seu objetivo é explicativo, uma vez que busca investigar os determinantes que contribuem para a participação da indústria mineral nas CGVs. Este tipo de pesquisa preocupa-se em identificar os fatores que determinam ou que contribuem para a ocorrência dos fenômenos (Gil, 2002).

\subsection{Descrição da amostra e das variáveis}

A seleção das variáveis foi feita a partir de indícios da literatura sobre a influência das mesmas no índice de participação nas CGVs. Uma delas (Produção Bruta) foi proposta para investigar se existe essa relação de causa e efeito. $O$ índice de participação nas CGVs ( $\mathrm{Pa}$ ) é a variável dependente do modelo e as demais variáveis são independentes, exceto as variáveis de Câmbio (Ca), Pib per-capita (PIB) e Renda dos Recursos Naturais (Ren) que foram consideradas variáveis de controle. A Tabela 1 mostra quais são estas variáveis, a definição das mesmas e a fonte da qual elas foram extraídas. 
Tabela 1

Variáveis do modelo

\begin{tabular}{|c|c|c|}
\hline Variável & Definição & Fonte \\
\hline \multicolumn{3}{|c|}{ Variável Dependente } \\
\hline $\begin{array}{l}\text { Participação da } \\
\text { indústria mineral } \\
\text { nas CGV (Pa) }\end{array}$ & $\begin{array}{l}\text { Mede a participação à jusante e a montante nas CGVs (neste caso, da } \\
\text { indústria mineral). O índice é calculado a partir do valor agregado doméstico } \\
\text { nas exportações estrangeiras e o valor agregado estrangeiro nas exportações } \\
\text { domésticas. Quanto maior o valor, maior a participação da indústria ou do } \\
\text { país na GVC. }\end{array}$ & OECD \\
\hline \multicolumn{3}{|c|}{ Variáveis Independentes } \\
\hline $\begin{array}{l}\text { Liberdade } \\
\text { Comercial (Li) }\end{array}$ & $\begin{array}{l}\text { O índice de liberdade comercial baseia-se em dois indicadores: a tarifa média } \\
\text { ponderada do comércio e as barreiras não tarifárias (incluindo quantidade, } \\
\text { preço, restrições regulatórias, alfandegárias e de investimento, e } \\
\text { intervenção direta do governo). }\end{array}$ & The World Bank \\
\hline $\begin{array}{l}\text { Investimento } \\
\text { Estrangeiro } \\
\text { Direto (IED) }\end{array}$ & $\begin{array}{l}\text { Mostra as entradas líquidas (novos investimentos menos desinvestimentos) } \\
\text { na economia relatada por investidores estrangeiros e é dividida pelo PIB. }\end{array}$ & The World Bank \\
\hline $\begin{array}{l}\text { Infra- Estrutura e } \\
\text { Logística (Ifr) }\end{array}$ & $\begin{array}{l}\text { A proxy corresponderá ao serviço de transporte do país. O transporte } \\
\text { abrange todos os serviços de transporte (marítimo, aéreo, terrestre, } \\
\text { hidroviário interno, oleoduto, espaço e transmissão de eletricidade) } \\
\text { realizados pelos residentes de uma economia para os de outra e que } \\
\text { envolvem transporte de passageiros, movimentação de mercadorias (frete), } \\
\text { aluguel de transportadoras com tripulação e serviços relacionados de } \\
\text { suporte e auxiliares. }\end{array}$ & The World Bank \\
\hline Inovação (In) & $\begin{array}{l}\text { A proxy de inovação utilizada será o número de pedidos de patentes } \\
\text { registrado por país. As estatísticas baseadas em patentes refletem o } \\
\text { desempenho inovativo de países, regiões e empresas, bem como outros } \\
\text { aspectos da dinâmica do processo de inovação. }\end{array}$ & The World Bank \\
\hline $\begin{array}{l}\text { Qualificação da } \\
\text { mão de obra } \\
\qquad(\mathrm{Qu})\end{array}$ & $\begin{array}{l}\text { A proxy é o número de matrículas no ensino médio. Esta taxa é a proporção } \\
\text { do total de matrículas em relação à população da faixa etária que } \\
\text { corresponde oficialmente ao nível de escolaridade mostrado. }\end{array}$ & The World Bank \\
\hline $\begin{array}{l}\text { Importações } \\
\text { intermediárias } \\
\text { reexportadas } \\
(\operatorname{Re}) \\
\end{array}$ & $\begin{array}{l}\text { As importações intermediárias reexportadas medem as importações } \\
\text { intermédias da indústria de um país que são incorporadas nas exportações } \\
\text { brutas de outra nação. }\end{array}$ & OECD \\
\hline $\begin{array}{l}\text { Diversificação } \\
\text { (Di) }\end{array}$ & Número de commodities minerais produzidas pela indústria mineral do país. & $\begin{array}{l}\text { United States } \\
\text { Geological } \\
\text { Survey (USGS) }\end{array}$ \\
\hline $\begin{array}{l}\text { Produção Bruta } \\
\text { (Pr) }\end{array}$ & $\begin{array}{l}\text { Refere- se a diferença entre a produção de uma indústria (neste caso, a } \\
\text { mineral) e a soma dos seus insumos intermediários de bens e serviços. }\end{array}$ & OECD \\
\hline \multicolumn{3}{|c|}{ Variáveis de Controle } \\
\hline Câmbio (Ca) & $\begin{array}{l}\text { A proxy será a taxa de câmbio efetiva real. Esta medida refere- se a taxa de } \\
\text { câmbio efetiva nominal dividida pelo índice de custos. }\end{array}$ & The World Bank \\
\hline $\begin{array}{l}\text { PIB per capita } \\
\text { (PIB) }\end{array}$ & O PIB per capita é o produto interno bruto dividido pela população do país. & The World Bank \\
\hline $\begin{array}{c}\text { Renda dos } \\
\text { Recursos } \\
\text { Naturais (Ren) }\end{array}$ & $\begin{array}{l}\text { Refere- se a contabilização da contribuição dos recursos naturais para a } \\
\text { produção econômica. Consiste na soma das rendas proveniente da extração } \\
\text { de petróleo, gás natural, carvão, minerais e insumos provenientes da } \\
\text { floresta. }\end{array}$ & The World Bank \\
\hline
\end{tabular}

Fonte: Elaborados pelos autores

A análise da Tabela 1 mostra que a fonte principal na qual a maioria dos dados foram extraídos foi banco de dados Trade in Value Added (TiVA) disponibilizado pela OECD. O conjunto de dados disponíveis nessa 
base medem os fluxos de comércio em termos do valor agregado internamente por um país para a produção de qualquer bem ou serviço que seja exportado. Eles auxiliam a investigar a competitividade das empresas, regiões e países nos mercados internacionais e setores específicos (De Backer \& Miroudot, 2014). Além disso, optou-se pela inclusão de variáveis de controle em busca de um melhor ajuste do modelo, uma vez que além das variáveis independentes, outros fatores tais como a taxa de câmbio e o PIB do país também podem exercer influência no índice de participação da indústria em questão.

O período analisado correspondeu aos anos de 2001 a 2015 e a coleta abrangeu um intervalo bienal. A escolha deste ínterim se deu pelo fato dos dados disponíveis no banco TiVa (OECD, 2018) abrangerem somente este período. O objeto de estudo consistiu em uma amostra de sessenta e dois países com diferentes níveis de desenvolvimento econômico. Em termos da análise da indústria mineral destes países, pode- se considerar que os dados utilizados para o modelo deste estudo serão representativos da realidade mundial, uma vez que esta amostra contém os países membros do G20. Além de abranger dois terços da população mundial, em 2018, somente estes países foram responsáveis por cerca de $85 \%$ da produção econômica mundial e $75 \%$ das exportações globais (CRS, 2019).

\subsection{Estratégia Empírica}

O software R foi utilizado para estimar o modelo deste estudo pelo fato de ser robusto e gratuito. As estimações foram feitas através da técnica de regressão com a estrutura dos dados em painel, já que havia variação entre os indivíduos (países) e ao longo do tempo na amostra, justificando assim este tipo de análise. Nesse sentido, a análise de regressão a partir de dados em painel, possibilita o entendimento da relação de uma variável específica com múltiplas variáveis de predição, oferecendo assim, modelos preditivos de diferenças de observações ao longo de uma série de tempo. Inicialmente, todas as variáveis foram normalizadas a fim de estreitar a amplitude das mesmas e assim evitar outilers que pudessem causar heterocedasticidade, interferindo assim na estimação do modelo. Abaixo é expresso o modelo de regressão múltipla a ser testado, onde é esperado um sinal negativo para a variável $\mathrm{Pr}$ e positivo para as demais: $y_{i t}=\beta_{0}+\beta_{1 \text { Pa }} x_{i t}+\beta_{2 \text { Li }} x_{i t}+\beta_{3 \text { IED }} x_{i t}+\beta_{4 \text { lf }} x_{i t}+\beta_{5 \text { In }} X_{i t}$ $+\beta_{6 \mathrm{Qu}} X_{i t}+\beta_{7 \mathrm{Re}} X_{i t}+\beta_{8 \mathrm{Di}} X_{i t}+\beta_{9 \mathrm{Pr}} X_{\mathrm{it}}+\beta_{10 \mathrm{Ca}} X_{i t}+\beta_{11 \mathrm{PlB}}$ $X_{i t}+\beta_{12 \text { Ren }} X_{i t}+\alpha_{i t}+u_{i t}$

Em que: $y_{i t}=$ Participação da indústria mineral nas CGVs; $\beta_{0}=$ intercepto; $\beta_{1}$ a $\beta_{9}=$ variáveis independentes; $\beta_{10}$ a $\beta_{12}=$ variáveis de controle, $\alpha_{i t}=$ fatores não observados constantes no tempo que afetam $y_{i t}$; $u_{i t}=$ erro idiossincrático.

Por outro lado, em função do número de variáveis, e a partir da análise da matriz de covariância (em anexo), optamos por utilizar a forma multinível para testar este modelo. Este formato assegura que a significância das variáveis não seja influenciada pela interferência de uma variável sobre outra. Dessa forma, o modelo (1) será decomposto em quatro submodelos para abranger as quatro categorias das variáveis mostradas na Figura 1.

\subsection{Testes de Especificação do Modelo}

Alguns testes de especificação foram realizados a fim de determinar qual seria o modelo ideal de estimação. $O$ primeiro deles foi o Teste $F$ o qual auxiliou determinar entre o uso do modelo Pooled e o Modelo de Efeitos fixos. Como o p valor foi menor que 0,05 a hipótese nula foi rejeitada, e, portanto, o Modelo Pooled não foi considerado. Em seguida, para definir entre o modelo de primeiras diferenças e o modelo de efeitos fixos, com base na eficiência do estimador, a segunda opção novamente se manteve.

Por último, o teste de Hausman foi utilizado para definir entre o modelo de efeito aleatório e o modelo de efeito fixo. Neste teste, se os efeitos fixos estão presentes, a estimação pelo modelo aleatório não será consistente. Como o $p$ valor foi maior que 0,05, a hipótese nula foi rejeitada, indicando a presença do efeito fixo. Para confirmar, o Teste Honda também não apontou a presença do efeito aleatório e por esta razão, a escolha novamente se deu pelo Modelo de Efeitos Fixos.

\section{RESULTADOS}

\subsection{Análise da Estatística Descritiva}

Uma etapa importante que antecede a estimação do modelo é a análise das estatísticas descritivas. $\mathrm{Na}$ Tabela 2 encontra- se os resultados médios de cada uma das variáveis, mínimo, máximo, mediana e número de observações. 
Tabela 2

Estatística Descritiva

\begin{tabular}{c|c|c|c|c|c}
\hline Variáveis & Mínimo & Máximo & Mediana & Média & Observações \\
\hline $\mathrm{Pa}$ & 0,000 & 1,000 & 0,332 & 0,355 & 496 \\
\hline $\mathrm{IED}$ & 0,000 & 1,000 & 0,049 & 0,074 & 494 \\
\hline $\mathrm{Li}$ & 0,000 & 1,000 & 0,806 & 0,770 & 486 \\
\hline $\mathrm{Ifr}$ & 0,000 & 1,000 & 0,288 & 0,325 & 457 \\
\hline $\mathrm{In}$ & 0,000 & 1,000 & 0,001 & 0,021 & 456 \\
\hline $\mathrm{Qu}$ & -0.1305 & 1,000 & 0,550 & 0,547 & 431 \\
\hline $\mathrm{Re}$ & 0,000 & 1,000 & 0,019 & 0,057 & 496 \\
\hline $\mathrm{Di}$ & 0,000 & 1,000 & 0,271 & 0,293 & 488 \\
\hline $\mathrm{Pr}$ & -0.0000185 & 1,000 & 0,006 & 0,006 & 495 \\
\hline \multicolumn{7}{|c|}{ Estatística descritiva da variável dependente "Pa" } \\
\hline Entre os grupos & 0,038115 & 0,802042 & & \\
\hline Dentro dos grupos & 0,376563 & 0,585442 & & \\
\hline
\end{tabular}

A análise da Tabela 2 aponta uma diferença significativa entre o mínimo e o máximo das variáveis - em especial, para a qualificação da mão de obra (Qu) e produção bruta. Isso indica uma alta discrepância entre os valores destas grandezas entre os países, além da presença de outliers. Quanto à variável dependente, Índice de participação da indústria mineral dos países nas CGVs (Pa), a Tabela 2 mostra que a média dessa variável é de 0,355 , enquanto que, o valor mínimo é de 0,000 e o máximo dessa participação é de 1,000. A estatística descritiva dentro dos grupos apontou que a participação da indústria mineral de um mesmo país variou significativamente ao longo dos quinze anos analisados. Isso sugere como esta indústria pode ser influenciada por fatores externos, sobretudo, por fatores macroeconômicos e estruturais.

Além disso, a estatística descritiva entre os grupos, ou seja, entre os países, aponta uma diferença considerável entre o mínimo e máximo da variável "Pa", mostrando que a participação da indústria mineral nas CGVs dos mesmos é desigual. Nesse sentido, as Figuras 2 e 3 também apontam essa diferença. Os valores do índice de participação ( $\mathrm{Pa})$ mostrados referem- se ao ano de 2015.
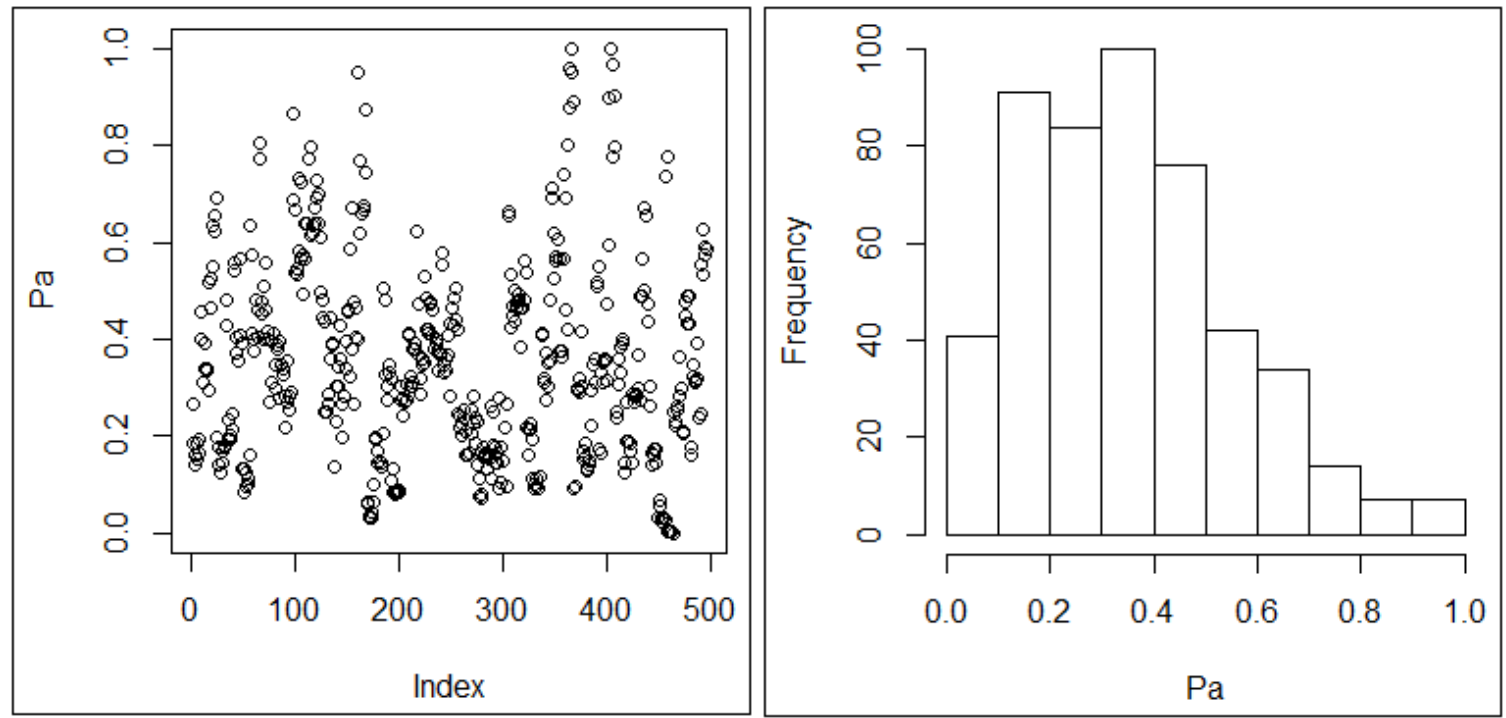

Figuras 2 e 3: Gráfico de bolhas e Histograma da Participação da indústria mineral dos países da amostra nas CGVs. 
A partir da análise da Figura 2, observa-se que se for traçada uma linha imaginária horizontal no valor de 0,5 no eixo das ordenadas da Figura 2 é possível inferir que das 496 observações realizadas nesta pesquisa, um número considerável dos países que compõe a amostra possui suas respectivas indústrias minerais pouco integradas nas CGVs. Se for realizado o mesmo procedimento no Histograma mostrado na Figura 3, mas dessa vez, traçando- se uma linha imaginária vertical na abcissa de valor 0,5 também é notável uma integração desigual desta indústria nestas.

\subsection{Estimativa do Modelo}

Após a identificação do modelo ideal para estimar a regressão, alguns testes foram realizados para identificar a presença de correlação serial e de efeitos individuais /temporais. A existência de alguns deles, exige que seja realizada a inferência robusta no modelo de efeito fixo para garantir que a significância do teste não seja afetada e o estimador seja eficiente. O teste condicional de Baltagi apontou a existência de correlação serial nos erros do modelo de efeito fixo. Da mesma forma, o teste de Durbin Watson e o teste Breush-Goldfrey indicaram a correlação serial.

A partir do resultado destes testes, os coeficientes da regressão foram calculados a partir do erro padrão robusto. Esse processo estima a matriz de covariância relaxando as hipóteses de homoscedasticidade e erros independentes, ao mesmo tempo que garante a robustez do estimador. A Tabela 3 apresenta o coeficiente das variáveis testadas:

Tabela 3

Estimação do modelo pelo método de efeito aleatório

\begin{tabular}{|c|c|c|c|c|c|c|c|c|c|c|}
\hline Variáveis & $\begin{array}{c}\text { Efeito da política } \\
\text { Macro-Econômica } \\
\text { Modelo } 1.1\end{array}$ & & $\begin{array}{l}\text { Efeito das } \\
\text { condições } \\
\text { estruturais } \\
\text { Modelo } 1.2\end{array}$ & & $\begin{array}{l}\text { Efeito do } \\
\text { Comércio } \\
\text { Exterior } \\
\text { Modelo } 1.3\end{array}$ & & $\begin{array}{l}\text { Efeito das } \\
\text { Características da } \\
\text { Indústria Mineral } \\
\text { Modelo } 1.4\end{array}$ & & $\begin{array}{c}\text { Modelo } \\
\text { Completo }\end{array}$ & \\
\hline $\mathrm{Li}$ & 0,106339 & . & & & & & & & 0,043514 & \\
\hline IED & 0,601623 & & & & & & & & 0,047561 & \\
\hline Ifr & & & $-0,14463$ & $*$ & & & & & $-0,18504$ & $*$ \\
\hline In & & & 0,394936 & & & & & & $-1,592122$ & $* * *$ \\
\hline Qu & & & 0,104263 & $* *$ & & & & & 0,127641 & \\
\hline $\mathrm{Re}$ & & & & & $-0,449144$ & & & & 0,290437 & $* *$ \\
\hline Di & & & & & & & $-0,203703$ & $* * *$ & $-0,062842$ & \\
\hline $\mathrm{Pr}$ & & & & & & & 1,023575 & & $-0,204767$ & $* * *$ \\
\hline $\mathrm{Ca}$ & $-0,114943$ & $* * *$ & $-0,177498$ & $* * *$ & $-0,136488$ & $* * *$ & -0.076279 & $* *$ & $-0,18814$ & $* *$ \\
\hline Pib & $-7,137003$ & $*$ & $-0,82387$ & & $-2,942263$ & & $-8,372641$ & $*$ & $-0,24903$ & $* *$ \\
\hline Ren & $-0,526494$ & $*$ & $-0,522633$ & $*$ & $-0,436419$ & $*$ & $-0,331675$ & & $-0,218707$ & $*$ \\
\hline
\end{tabular}

A Tabela 3 indica uma diferença de estimação para o modelo multinível e o modelo completo. Ao compará-los, observa- se uma diferença no nível de significância de determinadas variáveis, e até mesmo a não significância estatística de algumas delas. Isto ocorre, porque no modelo completo ocorre interferência de determinadas variáveis sobre as outras. Por esta razão, o modelo multinível será utilizado para a análise a seguir.

\section{DISCUSSÃO}

Dentre os muitos desafios enfrentados pelos países em desenvolvimento um deles é a estimação do grau de participação nas CGVs e os ganhos líquidos de valor agregado arrecadado, e por isso a importância das análises setoriais (Banga, 2013). Nesse sentido, os resultados mostrados a seguir lançam alguma luz nesta direção. Dos 62 países que foram analisados, somente apenas 28 deles têm sua indústria mineral integrada acima da média nas CGVs (superior a 0,355 conforme apontou a estatística 
descritiva), e 77\% dos países em desenvolvimento ${ }^{8}$ de acordo com o critério utilizado pelas Nações Unidas (United Nations, 2014)- estão abaixo deste valor (África do Sul, Arábia Saudita, Argentina, Brasil, Brunei Darussalam, Filipinas, Chile, China, Colômbia, Costa Rica, Índia, Indonésia, Malásia, México, Peru,
Rússia, Singapura, Tunísia e Turquia). Esta evidencia sugere que a atividade minerária dos países em desenvolvimento, em sua maioria, não tem uma participação efetiva nas CGVs. A Figura 4 apresenta os maiores índices de participação da indústria mineral mundial nas CGVs para o ano de 2015:

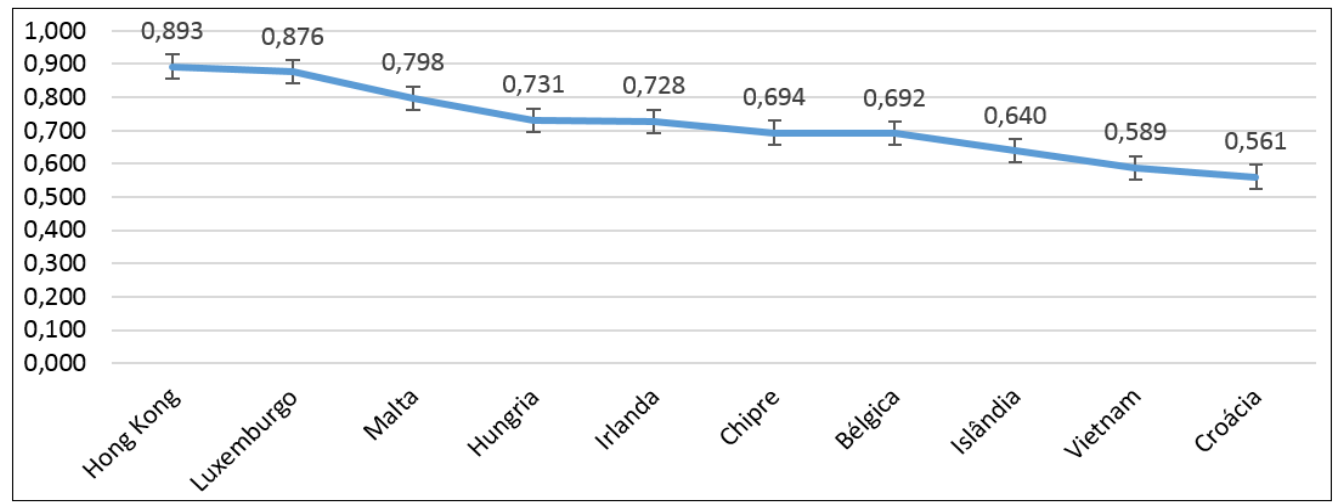

Figura 4: Ranking do posicionamento da indústria mineral mundial com melhor participação nas CGVs.

Como pode ser observado na Figura 4, neste ranking, prevalece países de economia desenvolvida (com exceção apenas de Hong Kong e Vietnan). Um achado interessante é que nenhum país com tradição na mineração ou que possua extensas reservas minerais constam nesta classificação. Apesar da demanda crescente por bens minerais e de grande parte dos países em processo de desenvolvimento serem grandes fontes de suprimento global, muitos deles ainda possuem baixa capacidade de extrair valor das cadeias de produção das quais estão inseridos. Muitas destas nações ainda limitam- se ao fornecimento de bens primários, em especial provenientes da mineração nas CGVs (Piorski \& Xavier, 2018; Makasheva et al., 2017).

Um exemplo concreto desta realidade é a Rússia, país que participa significativamente no mercado global de minerais e matérias-primas, e é considerado um dos principais exportadores de vários tipos de minério (Makasheva et al., 2017). No entanto, esse país não está presente entre os países mostrados na Figura 4 e o índice de participação de sua indústria mineral é de 0,173 , bem inferior à média mostrada na Tabela 2. O Brasil por exemplo, obteve um valor de 0,280, o qual poderia ser sem dúvida mais elevado, quando considerado seu potencial geológico e seu status de grande exportador de commodities minerais. Ou seja, o comércio de produtos intermediários a partir da indústria mineral é menos significativo no comércio total desses países.

A Islândia por exemplo, é um país que não possui reservas comprovadas de metais básicos, metais preciosos ou minerais industriais, e é altamente dependente das importações de inúmeras commodities minerais para atender à demanda doméstica (Perez, 2014). No entanto, essa nação ocupa o oitavo lugar como é mostrado na Figura 3. Muitos fatores podem justificar este resultado e a análise do desempenho da Bélgica auxilia a compreender a posição privilegiada da indústria mineral desses países. No caso belga, este país é um processador significativo de matérias-primas minerais e em 2014, respondeu por 7,6\% das importações de matérias-primas da União Europeia (UE) sendo que 75,9\% de todas as exportações da Bélgica foram para membros da UE (Perez, 2014). A presença significativa de siderúrgicas e metalúrgicas pressupõe a importação de bens minerais para posterior exportação em função do volume de minério que não seria em sua totalidade consumido pelo mercado doméstico.

\subsection{Política macroeconômica}

Quanto aos fatores que podem influenciar a participação da indústria mineral dos países

\footnotetext{
${ }^{8}$ De acordo com o critério utilizado pelas Nações Unidas (United Nations, 2014).
} 
Fatores Determinantes de Inserção nas Cadeias Globais de Valor: Uma Análise da Participação da Indústria Mineral

analisados nas CGVs, o resultado do modelo estimado auxilia nesta investigação. Em relação as variáveis da política macroeconômica, a análise da Tabela 3 mostra que a liberdade comercial (Li) foi significativa positivamente, o que confirma a importância da abertura comercial dos países que almejam ingressarem e participarem das CGVs conforme relatado em diversos estudos (Beverelli et al., 2019; De Backer \& Miroudot, 2014; Gereffi, 2014). A literatura CGV enfatiza que uma maior liberdade comercial reflete em menor barreiras comerciais, o que por sua vez, contribui para uma maior integração de todos os setores da economia nas CGVs. Gereffi (2014) por exemplo, mostrou que um elemento essencial do sucesso do México nas CGVs é o seu alto grau de abertura comercial. Este país tem acordos de livre comércio com 44 países, o que é mais do que o dobro da China e quatro vezes mais do que o Brasil.

Por outro lado, o Investimento Estrangeiro Direto (IED) não obteve significância estatística, contrariando diversos estudos que relata o papel deste fator na dinâmica de investimentos de empresas e como isso pode afetar na melhoria da participação junto as CGVs (Amendolagine et al., 2017; Staritz et al., 2016). No caso da indústria mineral, como em muitas outras, a participação junto as CGVs geralmente se dá pela integração vertical por meio do IED a partir de fusões e aquisições que as mineradoras multinacionais realizam sobre empresas estatais ou de pequeno porte (Smith, 2015; Tinta, 2017). A atração do IED para esta indústria em específico é adotado por muitos países, sobretudo, aqueles em desenvolvimento, para fomentar esta atividade. As políticas e leis atraentes e facilitadoras de IED são fundamentos essenciais para a mineração (Haddow, 2014).

Porém o fator que pode ter contribuído para a baixa significância desta variável neste estudo é o fato desta grandeza se referir ao investimento estrangeiro geral, direcionado para todos os setores do país, e não somente para a indústria mineral. Não foi possível localizar um proxy do IED específica para a indústria mineral que abrangesse toda a amostra e período analisado. Para se ter uma ideia da diferença que isso pode causar, no período de 2003 a 2014, a maior parcela do IED em novos empreendimentos no Brasil foi destinada ao setor de mineração e siderurgia- 21,4\% do total (Silva Filho, 2015). Ou seja, a proxy do IED para a indústria mineral mostraria de forma mais realista o efeito desses investimentos para a integração desta indústria nas CGVs, e possivelmente, mudaria o resultado obtido. Dessa forma, a Hipótese 1a foi validada enquanto que a hipótese $1 b$ foi rejeitada.

\subsection{Condições estruturais e tecnológicas}

No que diz respeito as variáveis relacionadas às condições estruturais, nossos resultados também não confirmaram a influência da Inovação (In) para a integração da indústria mineral nas CGVs. Novamente, a dificuldade de encontrar proxies para a inovação para o período analisado, e de forma específica para a mineração forçou a escolha do número de pedidos de patentes registrado por país como alternativa. Sendo assim, são necessários mais estudos que analisem essa relação no caso da indústria mineral, pois as evidências de outros setores apontam uma influência positiva considerável da inovação e avanço nas CGVs (Giuliani et al., 2005; Haakonsson, 2009).

Por outro lado, ressalta- se que os efeitos da inovação na indústria mineral demanda tempo para ser notado como um dos fatores responsáveis pela melhoria da participação desta indústria nas CGVs. A razão é que muitos dos registros de patentes observados para a atividade mineral demandam um período considerado para serem implementados a nível de indústria prejudicando assim, a percepção dos resultados. A nível de firma, em geral, são as mineradoras multinacionais que desenvolvem as principais inovações (que possibilitam o upgrading de produto e processo) e não as pequenas e médias empresas que se constituem como maioria nesta indústria. Da mesma forma, muitas das tecnologias desenvolvidas em centros de pesquisas de desenvolvimento mineral e universidades são feitas em escala piloto, e muitas vezes por falta de investimento, não têm continuidade ou não são comercializadas. Na Indonésia por exemplo, muitas universidades desenvolveram protótipos de processamento mineral e equipamentos de refino, mas nenhum deles foram aplicados pela indústria (Tijaja \& Faisal, 2014).

Em relação as demais variáveis "Qu" e "Ifr" ambas foram estatisticamente significativas. No primeiro caso, a Qualificação da mão de obra (Qu) mostrou impactar positivamente a participação nas CGVs, coadunando com os resultados de (Andrzej et al., 2019), os quais mostraram que este fator foi determinante para melhorar a participação das empresas nas CGVs de 29 países. Outras análises 
empíricas também confirmam que a educação e o desenvolvimento de capacidades técnicas são fundamentais para a integração nas CGVs, e consequentemente na transformação estrutural de um país (Ali e Msadfa, 2016; Lee e Malin, 2013).

Por outro lado, a infraestrutura (Ifr) teve um impacto negativo para a integração nas CGVs, o que contradiz as análises de Kaplinsky (2014), Morris et al. (2012) e Staritz et al., 2016). Os achados empíricos de Kaplinsky (2014) por exemplo, apontaram que o desenvolvimento de ligações na indústria mineral de nove economias africanas se deu em especial, pelo desenvolvimento da infraestrutura. Segundo este autor, este fator afeta não apenas o custo de exportação de recursos, mas também, a proteção natural oferecida aos fornecedores locais e seus custos de insumos e logística. Mais uma vez, acreditamos que a proxy utilizada, pela ausência de um indicador que cobrisse o período analisado, foi responsável por este resultado inesperado.

O motivo é que o valor da proxy de serviço de transporte, tende a ser tanto maior quanto mais serviços de transporte (sejam eles marítimo, aéreo, terrestre, hidroviário interno, oleoduto, etc) são realizados pelo país analisado para outro parceiro. A questão é que, em função da característica do setor extrativista (de produção e exportação em larga escala) os serviços de transporte para a exportação de commodities tende a ser mais intenso do que por exemplo, a exportação de bens manufaturados e com alto conteúdo tecnológico. Ou seja, neste caso, não se trata da intensidade do serviço de transporte, o qual seria um demonstrativo da boa infraestrutura e logística do país, mas sim, do bem que está se transportando. Diante destes resultados, as Hipóteses $2 a$ e $2 b$ foram rejeitadas, enquanto que a Hipótese 2 c foi suportada a partir da estimativa do modelo.

\subsection{Comércio Exterior da indústria mineral}

Quanto à variável relacionada ao comércio exterior "Re", a qual refere- se as importações intermediárias reexportadas da indústria mineral, os resultados não apontaram influência da mesma para a participação da indústria mineral nas CGVs. Assim, a hipótese Hipótese 3a também foi rejeitada. Este achado difere das evidências encontradas por Dean et al. (2008) e Sturgeon \& Gereffi (2009), os quais argumentam que o aumento no comércio de bens intermediários impactou na fragmentação geográfica do processo de produção e consequentemente na integração junto às CGVs. Dean et al. (2008) mostrou que em vez de se engajar na substituição progressiva de importações à medida que as capacidades domésticas aumentavam -como prevê a maioria das teorias de desenvolvimento- a China aumentou sua dependência de intermediários importados à medida que as exportações aumentaram. Essa estratégia contribuiu para o avanço de inúmeros setores e consequentemente no aumento da participação deste país nas CGVs.

No caso deste estudo, a justificativa para a irrelevância da variável "Re" para contribuir com a participação da indústria mineral dos países analisados nas CGVs pode estar associada ao fato de que esta estratégia ainda é pouco praticada em muitos países em desenvolvimento da amostra analisada. A política de substituição das importações pressupõe a produção e agregação de valor doméstico na totalidade da produção de um determinado bem, em detrimento da importação de um bem intermediário e sua posterior agregação de valor. Apesar de altamente condenada na literatura CGV (Gereffi, 2014; Kaplinsky, 2014), esta política ainda é praticada em muitos países, e uma prova disso, é que o valor das importações intermediárias reexportadas e valor adicionado interno incorporado nas exportações relacionadas a indústria mineral é destoante entre os países.

De acordo com o banco de dados TiVa da OECD (2018), o valor da "Re" em 2015 para a Rússia, Arábia Saudita, Japão e Coréia foram respectivamente $3.623,00 ; 295,4 ; 24.920,4$ e $47.225,4$ ao passo que o valor agregado doméstico foi de 106.656,5; 139.024,8; 474,1 e 306,2 (em milhões de dólares) para esses mesmos países. Ou seja, as duas economias desenvolvidas neste exemplo, dedicamse em agregar valor aos bens importados, e não na produção doméstica. Esta é uma das estratégias "chaves" para melhorar a participação de indústrias, e consequentemente de uma nação nas CGVs (Milberg, 2013).

\subsection{Características da indústria mineral}

Por fim, no que concerne as variáveis relacionadas as características da indústria mineral, o resultado do modelo não apontou significância estatística relacionando a produção bruta de minério $(\mathrm{Pr})$ com o aumento da participação da indústria mineral nas CGVs, enquanto que para a variável "Di" relacionada 
Fatores Determinantes de Inserção nas Cadeias Globais de Valor: Uma Análise da Participação da Indústria Mineral

a diversificação produtiva houve uma significância estatística negativa. Assim, as Hipóteses 4a e 4b não foram validadas. No primeiro caso, esta variável foi escolhida para ser investigada pelo fato dela não ter sido identificada nos estudos empíricos que versam sobre os determinantes de participação nas CGVs.

Esperava- se uma influência deste fator pelo fato de que os países dependentes de exportação de commodities minerais serem em geral aqueles que possuem uma produção bruta elevada de minério. Muitos deles dependem em parte das exportações desses bens e a mineração contribui significativamente para o produto interno bruto (Makasheva et al., 2017). No entanto, o resultado gerado pode ser compreendido em função da queda no preço das commodities que teve início com crise financeira mundial de 2008 e teve reflexos até meados de 2013. Em função da diminuição da demanda estrangeira por bens minerais a produção bruta teve oscilações bruscas ao longo do período da análise, o que possivelmente influenciou no resultado desta variável.

Em relação a variável de diversificação "Di", sua influência negativa no nível de participação nas CGVs diferiu- se dos achados de Ali e Msadfa, (2016), Staritz et al. (2016) e Tinta (2017). Tinta (2017), por exemplo, constatou em seu estudo sobre o papel do comércio intra-regional na integração da África nas CGVs que o aumento da diversificação gerou acréscimo no valor agregado enquanto.Já Staritz et al. (2016), apresentaram evidências de que a diversificação do mercado ofereceu mais oportunidades de exportação no setor de roupas da Etiópia. Porém o resultado obtido no presente estudo pode ser compreendido em função da estrutura da indústria mineral global mostrada nos relatórios da United States Geological Survey (USGS, 2020).

A análise desses documentos mostra que os bens minerais produzidos e declarados pelos países englobam a produção de minério em vários estágios de valor adicionado, desde o minério in natura até os estágios de processamento com maior valor agregado. Assim, um país pode ter alta diversificação na produção de bens minerais, e, no entanto, grande parte deles advirem da produção bruta e seguirem para a exportação sem adição de conteúdo estrangeiro. Em outras palavras, se tratando da indústria mineral, a diversificação do portfólio só terá efeito positivo para a integração nas CGVs se não prover da adição da exportação bruta de outros bens minerais além daqueles já produzidos pelo país.

Um caso concreto que ilustra este raciocínio é o da indústria mineral da Croácia, a qual obteve o décimo maior índice de participação nas GGVs ("Pa") entre os sessenta e dois países analisados (Figura 3). No entanto, esse país possui um déficit comercial em bens minerais e recentemente, deixou de extrair minérios de metais. A produção da indústria mineral deste país ocorre basicamente a partir de matériasprimas secundárias - advindas da reciclagem doméstica e da importação (Perez, 2014). Ou seja, além de ter baixa diversificação de bens minerais os dados sugerem que as commodities minerais importadas pela Croácia além de serem essenciais para a economia desse país ainda contribuem para a participação efetiva de sua indústria mineral nas CGVs.

A partir desta discussão, pode-se fazer a seguinte leitura, com base no resultado do modelo econométrico apresentado na Tabela 3: Os países que possuem maior abertura comercial e melhor qualificação de mão de obra têm uma maior participação de suas respectivas indústrias minerais nas CGVs. Estas evidências estão em consonância com a literatura CGV vigente e reforçam os achados de outros estudos que analisaram diferentes tipos de indústrias ou a participação a nível de país ou regional. Por outro lado, a infra- estrutura e a diversificação produtiva impactaram negativamente a participação da indústria mineral nas CGVs o que diverge consideravelmente de muitos estudos. No entanto, estes resultados são compreendidos quando considera- se as características intrínsecas da indústria mineral, como grande escala de produção e baixo valor agregado.

\section{CONCLUSÃO}

Em um contexto onde países buscam cada vez mais se inserirem na dinâmica do comércio internacional, o setor extrativista é fundamental para alimentar o processo produtivo ao longo das cadeias globais de valor (CGVs). De forma especial, destacase a indústria mineral, uma atividade econômica essencial para muitas economias emergentes e que ainda é pouco analisada sob a lente teórica das CGVs. Utilizando a técnica de regressão múltipla e empregando uma estrutura de dados em painel para o período de 2001 a 2015 referente a sessenta e dois países, este estudo buscou investigar os 
determinantes para a participação da indústria mineral mundial nas CGVs dos países da amostra.

A partir da estimação do modelo de efeito fixo, discutimos a influência das variáveis selecionadas sobre o índice de participação ao longo destas cadeias. Nossos achados sugerem que os fatores determinantes para a participação da indústria mineral nas CGVs nos países analisados são a abertura comercial e a qualificação da mão de obra. Por outro lado, a infraestrutura e a diversificação produtiva, impactam negativamente. Neste último caso, os resultados diferem em grande parte de muitos estudos empíricos da literatura CGV, o que reforça a contribuição teórica deste estudo, além de demonstrar em certos aspectos, as características intrínsecas da indústria mineral em relação as demais. Buscamos assim contribuir com a literatura CGV apresentando evidências empíricas sobre os determinantes de participação nestas cadeias, pois conforme ressaltou Antràs \& Chor (2018), a identificação e análise desses fatores ainda permanecem sem respostas e merecem atenção.

Além disso, as análises descritivas permitiram identificar quais países têm a indústria mineral melhor posicionada nas CGVs. Os resultados apontaram que a indústria mineral de $77 \%$ dos países em desenvolvimento tem uma participação abaixo da média nas CGVs e que os países com maior participação não são os aqueles com tradição na atividade mineral. Isso mostra a importância de políticas industriais que contribuam para a inserção desta indústria em níveis mais elevados nas CGVs e que façam jus a potencialidade mineral que muitos países possuem e dos quais, muitos, não extraem o devido valor a partir desta atividade. Na perspectiva "GVC approach" estes resultados corroboram a necessidade de upgrading para a indústria mineral destes países, em busca de uma maior captura de valor, e consequentemente, de maior participação nas CGVs. Em especial no caso brasileiro, um dos principais desafios é aumentar o conteúdo tecnológico das exportações para realizar o upgrading de função no setor extrativista (Milberg, Jiang \& Gereffi, 2014).

Dessa forma, buscamos cooperar para o entendimento da questão do porquê de algumas indústrias minerais de determinados países estarem melhores inseridas nas CGVs do que outras, mesmo que esses não sejam grandes produtores de bens minerais. Nossos achados sustentam que os ganhos de uma mesma indústria na dinâmica CGV pode ser desigual entre os países, em especial nas economias emergentes, assim como mostrado nos estudos de Banga (2013), Kersan-Škabić (2019), dentre outros. De maneira especial, ressaltamos a importância de políticas que promovam a qualificação da mão de obra para esta indústria, em especial, o desenvolvimento de centros tecnológicos de pesquisa mineral e expansão de cursos técnicos, superiores e de pós-graduação. De modo específico no Brasil, conforme apontou o plano nacional de mineração (20011- 2030), há um déficit de profissionais especialistas para a pesquisa e beneficiamento mineral, além de pesquisadores para o desenvolvimento de novas tecnologias ligadas à mineração.

Ademais, as políticas industriais devem se concentrar na abertura comercial, promovendo sobretudo, acordos comerciais regionais, em especial entre os grandes países produtores de minério. A literatura recente vem apontando uma tendência crescente das CGVs se tornarem cada vez mais locais do que globais. Dessa forma, estimulamos estudos futuros que aprofundem mais sobre esta temática, sobretudo, incorporando outros fatores que não foram citados neste estudo, mas que podem trazer insighs valiosos para esta discussão. Por exemplo, as ligações da indústria mineral com setores à jusante e à montante, o perfil dos fornecedores locais e das empresas mineradoras (principalmente em termos de grau de propriedade), etc.

Ressaltamos como limitações deste trabalho, a falta de dados atuais para a maioria das variáveis investigadas, o que fez com que os dados mais recentes se referissem ao ano de 2015. Além disso, a indisponibilidade de dados específicos para a indústria mineral fez com que algumas proxies relativas "a nível de país" fossem utilizadas para retratar a realidade desta indústria. Nesse sentido, outras variáveis também com poder explicativo sobre a participação da indústria mineral nas CGVs não puderam ser utilizadas pela indisponibilidade de dados específicos para esta indústria. 
O presente trabalho foi realizado com apoio da Coordenação de Aperfeiçoamento de Pessoal de Nível Superior - Brasil (CAPES) - Código de Financiamento 001.

\section{REFERÊNCIAS}

Ali, A. A., \& Msadfa, Y. (2016). Industrial policy, structural change and global value chains participation: Case study of Morocco, Tunisia and Egypt. Policy Paper, OCP Policy Center, Rabat Morocco.

Amendolagine, V., Presbitero, A. F., Rabellotti, R., Sanfilippo, M., \& Seric, A. (2017). FDI, global value chains, and local sourcing in developing countries. International Monetary Fund (IFM)Working Paper, No. $17 / 284$, 40p.

Andrzej, C., Jan Jakub, M., \& Krzysztof, S. (2019). What matters for firms' participation in Global Value Chains in Central and East European countries? Equilibrium. Quarterly Journal of Economics and Economic Policy, 14(3), 481-502. https://doi.org/10.24136/eq.2019.023

Antràs, P., \& Chor, D. (2018). On the measurement of upstreamness and downstreamness in global value chains. NBER Working Papers 24185, National Bureau of Economic Research, Inc.

Antràs, P., Chor, D., Fally, T., \& Hillberry, R. (2012). Measuring the upstreamness of production and trade flows. American Economic Review, 102(3), 412-416. http://dx.doi.org/10.1257/aer.102.3.412

Balasubramanian, A. (2016). An overview of mining methods. University of Mysore. https://10.13140/RG.2.2.15761.63845

Bamber, P., Fernandez-Stark, K., \& Gereffi, G. (2016). Peru in the mining equipment global value chain: Opportunities for Upgrading. The World Bank, $43 p$.

Banga, R. (2013). Measuring value in global value chains. Background paper RVC-8. Geneva: UNCTAD.

Beverelli, C., Koopman, R. B., Stolzenburg, V., \& Neumueller, S. (2019). Domestic value chains as stepping stones to global value chain integration. The World Economy.
Bravo-Ortega, C., \& Muñoz, L. (2018). Mining services suppliers in Chile: A regional approach (or lack of it) for their development. Resources Policy. https://doi.org/10.1016/i.resourpol.2018.06.001

Caliendo, L., \& Parro, F. (2015). Estimates of the Trade and Welfare Effects of NAFTA. The Review of Economic Studies, 82(1), 1-44. https://doi.org/10.1093/restud/rdu035

CNI.2012. Mineração e economia verde. Confederação Nacional da Indústria. Cadernos setoriais Rio $+20.69 p$.

De Backer, K., \& Miroudot, S. (2014). Mapping global value chains. European Central Bank, Working Paper Series, No. 1677.

Dean, J. M., Fung, K. C., \& Wang, Z. (2008). How vertically specialized is Chinese trade? Office of economics working paper, No. 2008-09-D, Washington.

Del Prete, D., \& Rungi, A. (2017). Organizing the global value chain: A firm-level test. Journal of International Economics, 109, 16-30. https://doi.org/10.1016/j.jinteco.2017.08.003

Dolan, C. S., \& Tewari, M. (2001). From What We Wear to What We Eat Upgrading in Global Value Chains. IDS Bulletin, 32(3), 94-104. https://doi.org/10.1111/j.1759-

5436.2001.mp32003010.x

Fally, T. (2011). On the Fragmentation of Production in the US. University of Colorado mimeo.

Fessehaie, J. (2012). What determines the breadth and depth of Zambia's backward linkages to copper mining? The role of public policy and value chain dynamics. Resources Policy, 37(4), 443-451. https://doi.org/10.1016/i.resourpol.2012.06.003

Fleury, A., \& Fleury, M. (2001). Alternatives for industrial upgrading in global value chains: the case of the plastics industry in Brazil. IDS Bulletin, 32(3), 116-126. 
Fortier, S., Thomas, C., McCullough, E., \& Tolcin, A. (2018). Global Trends in Mineral Commodities for Advanced Technologies. Natural Resources Research, 27(2), 191-200. https://doi.org/10.1007/s11053017-9340-9

Gereffi, G. (2014). A global value chain perspective on industrial policy and development in emerging markets. Duke Journal of Comparative \& International Law, 24(3), 433.

Gereffi, G. (2018). The emergence of global value chains: Ideas, institutions, and research communities. Global value chains and development: Redefining the contours of 21st century capitalism, 1-39.

Gereffi, G., Humphrey, J., \& Sturgeon, T. (2005). The governance of global value chains. Review of international political economy, 12(1), 78-104. https://doi.org/10.1080/09692290500049805

Gereffi, G., \& Korzeniewicz, M. (1994). Commodity chains and global capitalism. ABC-CLIO.

Gereffi, G., \& Lee, J. (2016). Economic and Social Upgrading in Global Value Chains and Industrial Clusters: Why Governance Matters. Journal of Business Ethics, 133(1), 25-38. https://doi.org/10.1007/s10551-014-2373-7

Gil, A. C. (2002). Como elaborar projetos de pesquisa, vol. 4, São Paulo: Atlas.

Giuliani, E., Pietrobelli, C., \& Rabellotti, R. (2005). Upgrading in Global Value Chains: Lessons from

Latin American Clusters. World Development, 33(4), 549-573.

https://doi.org/10.1016/j.worlddev.2005.01.002

Greenville, J., \& Kawasaki, K. (2018). Agro-food trade, GVCs and agricultural development in ASEAN. https://doi.org/10.1787/89d40ebb-en

Greenville, J., Kawasaki, K., \& Beaujeu, R. (2017). A method for estimating global trade in value added within agriculture and food value chains. OECD Food, Agricultureand Fisheries Papers, No. 99, OECD Publishing,

Paris.http://dx.doi.org/10.1787/f3a84910-en
Haakonsson, S. J. (2009). 'Learning by importing' in global value chains: upgrading and South-South strategies in the Ugandan pharmaceutical industry. Development Southern Africa, 26(3), 499-516. https://doi.org/10.1080/03768350903086861

Haddow, K. 2014. How best can mining be a catalyst for diversifying economies? Mineral Economics, 27(2), 149-151.

Heery, D., O'Donoghue, C., \& Fathartaigh, M. Ó. (2016). Pursuing Added Value in the Irish Agri-Food Sector: An Application of the Global Value Chain Methodology. Proceedings in Food System Dynamics, 161-179.

Henckens, M. L. C. M., Driessen, P. P. J., \& Worrell, E. (2014). Metal scarcity and sustainability, analyzing the necessity to reduce the extraction of scarce metals. Resources, Conservation \& Recycling, 93, 1-8. https://doi.org/10.1016/j.resconrec.2014.09.012

Heron, T., Prado, P., \& West, C. (2018). Global Value Chains and the Governance of 'Embedded' Food Commodities: The Case of Soy. Global Policy, 9(S2), 29-37. https://doi.org/10.1111/1758$\underline{5899.12611}$

Hummels, D., Ishii, J., \& Yi, K.-M. (2001). The nature and growth of vertical specialization in world trade. Journal of international Economics, 54(1), 7596.

Humphrey, J., \& Schmitz, H. (2002). How does insertion in global value chains affect upgrading in industrial clusters? Regional studies, 36(9), 10171027.

Kaplinsky, R. (2014). Shudder: The challenges to "industrial policies" in the early 21 st century in low and middle income economies. International Business and Sustainable Development, Volume 8.

Katz, J., \& Pietrobelli, C. (2018). Natural resource based growth, global value chains and domestic capabilities in the mining industry. Resources Policy, 58, 11-20.

Kersan-Škabić, I. (2019). The drivers of global value chain (GVC) participation in EU member states. 
Fatores Determinantes de Inserção nas Cadeias Globais de Valor: Uma Análise da Participação da Indústria Mineral

Economic research-Ekonomska istraživanja, 32(1), 1204-1218.

Koopman, R., Powers, W., Wang, Z., \& Wei, S.-J. (2010). Give credit where credit is due: Tracing value added in global production chains. National Bureau of Economic Research, Working Paper No.16426, Cambridge.

Kummritz, V., Taglioni, D., \& Winkler, D. (2017). Economic upgrading through global value chain participation: which policies increase the value added gains? The World Bank. Policy Research working paper; No. WPS 8007.

Landesmann, M. A., \& Stöllinger, R. (2019). Structural change, trade and global production networks: An 'appropriate industrial policy' for peripheral and catching-up economies. Structural Change and Economic Dynamics, 48, 7-23. https://doi.org/10.1016/i.strueco.2018.04.001

Lee, Soohyung and Benjamin Malin. 2013. "Education's Role in China's Structural Transformation." Journal of Development Economics 101:

$148-166$

https://doi.org/10.1016/j.jdeveco.2012.10.006

Makasheva, N. P., Makasheva, Y. S., Boyarko, G. Y., $\&$ Khatkov, V. Y. (2017). Recent trends in the fl ows of minerals commodities. Gornyi Zhurnal(4), 33-38. https://doi.org/10.17580/gzh.2017.04.06

Masunda, S., \& Mupaso, N. (2019). A microeconometric analysis of factors affecting global value chain participation in Zimbabwe. Cogent Economics \& Finance, 7(1). https://doi.org/10.1080/23322039.2019.1682746

Mikhailov, A., Marion Filho, P. J., Mikhailova, I., \& dos Santos, L. G. (2017). Inserção dos países BRICS nas cadeias globais de valor (1995-2011). Estudos do CEPE(46), 58-74.

Milberg, W. (2013). Industrial policy when global value chains matter. Department of Economics New School for Social Research, Presentation at UNCTAD Working Group.

Morris, M., \& Fessehaie, J. (2014). The industrialisation challenge for Africa: Towards a commodities based industrialisation path. Journal of
African Trade, 1(1), 25-36. https://doi.org/10.1016/i.joat.2014.10.001

Morris, M., Kaplinsky, R., \& Kaplan, D. (2012). "One thing leads to another"-Commodities, linkages and industrial development. Resources Policy, 37(4), 408-416.

https://doi.org/10.1016/j.resourpol.2012.06.008

OECD. 2018. Trade in Value Added (TiVA): Principal indicators. Recuperado de https://stats.oecd.org/Index.aspx?DataSetCode=TIV A_2016_C1. Acesso 04 de junho de 2020.

Pahl, S., \& Timmer, M. P. (2019). Do Global Value Chains Enhance Economic Upgrading? A Long View. The Journal of Development Studies, 1-23.

Perez, A.A. The Mineral industry. U.S. (2014). Geological Survey Minerals Yearbook.

Pietrobelli, C., Marin, A., \& Olivari, J. (2018). Innovation in mining value chains: New evidence from Latin America. Resources Policy, Elsevier, 58(C),1-10.

Piorski, K. A. O. d. S., \& Xavier, C. L. (2018). Especialização em recursos naturais e cadeias globais de valor (1995 e 2009). Economia e Sociedade, 27(1), 89-127.

Purcell, T., Martinez-Esguerra, E., \& Fernandez, N. (2018). The value of rents: global commodity chains and small cocoa producers in Ecuador. Antipode, 50(3), 641-661. https://doi.org/10.1111/anti.12380

Reis, C. d. B., \& Almeida, J. (2014). A inserção do Brasil nas cadeias globais de valor comparativamente aos BRIICS. Campinas: Instituto de Economia, UNICAMP.

Silva Filho, E. B. d. 2015. Trajetória recente do investimento estrangeiro direto e em carteira no Brasil. Boletim de Economia e Política Internacional (BEPI), n.19.

Smith, F. (2015). Natural resources and global value chains: What role for the WTO? International Journal of Law in Context, 11(2), 135-152. https://doi.org/10.1017/S1744552315000038 
Staritz, C., Plank, L., \& Morris, M. (2016). Global Value Chains, Industrial Policy, and Sustainable Development-Ethiopia's Apparel Export Sector. Country Case Study, Geneva: International Centre for Trade and Sustainable Development (ICTSD).

Stubrin, L. (2017). Innovation, learning and competence building in the mining industry. The case of knowledge intensive mining suppliers (KIMS) in Chile. Resources Policy, 54, 167-175. https://doi.org/10.1016/j.resourpol.2017.10.009

Sturgeon, T. J., \& Gereffi, G. (2009). Measuring success in the global economy: international trade, industrial upgrading, and business function outsourcing in global value chains: an essay in memory of Sanjaya Lall. Transnational Corporations, 18(2), 1. https://doi.org/10.18356/64e03043-en

Sturgeon, T. J., Nielsen, P. B., Linden, G., Gereffi, G., Brown, C., Mattoo, A., Wang, Z., \& Wei, S. (2013). Direct measurement of global value chains: collecting product-and firm-level statistics on value added and business function outsourcing and offshoring. In Trade in Value Added: Developing New Measures of Cross-Border Trade (pp. 291 - 321). Washington: The World Bank and CEPR.

Tejada, P., Santos, F. J., \& Guzmán, J. (2011). Applicability of global value chains analysis to tourism: issues of governance and upgrading. The Service Industries Journal, 31(10), 1627-1643. https://doi.org/10.1080/02642069.2010.485642

The World Bank. (2019). Indicators. Recuperado de https://data.worldbank.org/indicator. Acesso 08 de junho de 2020.

Thorstensen, V., Ferraz, L., \& GUTIERRE, L. (2014). Brasil nas cadeias globais de valor. A inserção do Brasil nas cadeias globais de valor. Rio de Janeiro: Cebri.

Tijaja, J., \& Faisal, M. (2014). Industrial policy in Indonesia: A global value chain perspective. Asian
Development Bank Economics Working Paper Series(411).

Tinta, A. A. (2017). The determinants of participation in global value chains: The case of ECOWAS. Cogent Economics \& Finance, 5(1). https://doi.org/10.1080/23322039.2017.1389252

UNCTAD. (2016). Commodities at a Glance. 2016. United Nations Conference on Trade and Development.Recuperado https://unctad.org/en/Pages/SUC/Commodities/SUC -Commodities-at-a-Glance.aspx . Acesso em: 13 de junho de 2020.

United Nations. (2014). World Economic Situation and Prospects 2014. Recuperado de https://www.un.org/en/development/desa/policy/w esp/wesp current/2014wesp country classification .pdf . Acesso 10 de junho de 2020.

USGS. (2020). International Minerals Statistics and Information. Recuperado https://www.usgs.gov/centers/nmic/internationalminerals-statistics-and-information. Acesso 06 de junho de 2020.

Vlckova, J., \& Thakur-Weigold, B. S. (2019). Global value chains in the MedTech industry. A comparison of Switzerland and the Czech Republic. International Journal of Emerging Markets, 15(1), 70 - 92. https://doi.org/10.1108/IJOEM-05-2017-0179

Wang, X., Liu, Z., LV, Y., \& Zhao, C. (2019). Trade Barriers and Participation in the Global Value Chain: An Empirical Study Based on Anti-dumping toward China. China \& World Economy, 27(2), 86-106. https://doi.org/10.1111/cwe.12276

Wang, Z., Wei, S.-J., Yu, X., \& Zhu, K. (2017). Measures of participation in global value chains and global business cycles. National Bureau of Economic Research, Working Paper 23222, Cambridge. 


\title{
Sobre os Autores:
}

Ludmila Martins Floris - Universidade Federal de Lavras - UFLA, Minas Gerais, MG (Brasil). E-mail: luddellamancha@yahoo.com.br Orcid id: https://orcid.org/0000-0002-9172-8130

Cristina Lélis Leal Calegário - Universidade Federal de Lavras - UFLA, Minas Gerais, MG (Brasil). E-mail: ccalegario@ufla.br Orcid id: https://orcid.org/0000-0003-2579-8744

Ednilson Sebastião Ávila - Universidade Federal de Lavras - UFLA, Minas Gerais, MG (Brasil). E-mail: ednilson.avila@ufla.br Orcid id: https://orcid.org/0000-0002-3448-6841

Rafaela Maiara Caetano - Universidade Federal de Lavras - UFLA, Minas Gerais, MG (Brasil). E-mail: rafa.caet.94@gmail.com Orcid id: https://orcid.org/0000-0003-3933-1440

\section{COUNTRIES PARTICIPATION IN GLOBAL VALUE CHAINS: AN ANALYSIS OF THE DETERMINANT FACTORS IN THE MINERAL INDUSTRY}

\author{
Ludmila Martins Floris, Cristina Lélis Leal Calegário, Ednilson Sebastião Ávila, Rafaela Maiara Caetano \\ Universidade Federal de Lavras - UFLA, Minas Gerais, MG (Brasil)
}

\section{ARTICLE DETAILS}

\section{Article history:}

Received: 10 December 2019

Accepted: 30 June 2020

Available online August: 01 th 2020

\section{Double Blind Review System}

\section{Scientific Editor}

Ilan Avrichir

\section{Key words}

Global Value Chains

Participation

Mineral Industry

Panel Data

Fixed Effect Model

\begin{abstract}
Objective: To investigate the determinants for the participation of the mineral industry in the global value chains (GVCs) of the countries that will be analyzed.

Method: With an explanatory nature and quantitative approach, this study used multiple regression as a statistical technique using the Fixed Effect Model. The data structure was in a panel referring to sixty-two countries for the period from 2001 to 2015.

Main results: The results showed that $77 \%$ of developing countries have a low share of their respective mineral industries in GVCs compared to the average presented in the sample countries. Also, the estimation of the model suggests that the commercial opening and the qualification of the workforce are fundamental to increase the participation of this industry in CGVs.

Relevance/originality: The mineral industry is strategic for many countries and plays an indispensable role throughout CGVs as one of the main suppliers of inputs. Despite this, few studies analyze this industry under the theoretical lens of CGVs. Theoretical/methodological contributions: This study seeks to expand the CGV literature by providing evidence of which factors contribute to the participation of the mineral industry in these chains.

Social/management contributions (optional): Possible paths are presented that can improve the participation of this industry in GVCs.
\end{abstract}




\title{
PARTICIPACIÓN EN EL PAÍS EN CADENAS DE VALOR MUNDIALES: UN ANÁLISIS DE LOS FACTORES DETERMINANTES EN LA INDUSTRIA MINERA
}

\author{
Ludmila Martins Floris, Cristina Lélis Leal Calegário, Ednilson Sebastião Ávila, Rafaela Maiara Caetano \\ Universidade Federal de Lavras - UFLA, Minas Gerais, MG (Brasil)
}

\section{HISTORIA DEL ARTÍCULO}

Historia del Artículo:

Recibido: 10 de Diciembre de 2019

Aceptado: 30 de Junio de 2020

Disponible en línea: 01 de Agosto 2020

Double Blind Review System

Editor Científico

Ilan Avrichir

\section{Palabras-clave:}

Cadenas globales de valor

Participación

Industria Minera

Panel de datos

Modelo de efecto fijo

\begin{abstract}
RESUMEN
Objetivo: investigar los determinantes para la participación de la industria minera en las cadenas de valor globales (CGV) de los países que se analizarán. Método: con una naturaleza explicativa y un enfoque cuantitativo, este estudio utilizó la regresión múltiple como técnica estadística utilizando el modelo de efectos fijos. La estructura de datos se encontraba en un panel que hacía referencia a sesenta y dos países para el período comprendido entre 2001 y 2015.

Resultados principales: Los resultados mostraron que el 77\% de los países en desarrollo tienen una baja participación de sus respectivas industrias mineras en las CGV en comparación con el promedio presentado en los países de la muestra. Además, la estimación del modelo sugiere que la apertura comercial y la calificación de la fuerza laboral son fundamentales para aumentar la participación de esta industria en los CGV. Relevancia / originalidad: la industria minera es estratégica para muchos países y desempeña un papel indispensable en los CGV, ya que es uno de los principales proveedores de insumos. A pesar de esto, hay pocos estudios que analicen esta industria bajo la lente teórica de los CGV. Contribuciones teóricas / metodológicas: este estudio busca expandir la literatura de CGV al proporcionar evidencia de qué factores contribuyen a la participación de la industria minera en estas cadenas. Contribuciones sociales / de gestión (opcional): se presentan posibles caminos que pueden mejorar la participación de esta industria en las CGV.
\end{abstract}

\section{Como citar este artigo:}

Floris, L., Calegário, C., Ávila, E., \& Caetano, R. (2020). Fatores Determinantes de Inserção nas Cadeias Globais de Valor: Uma Análise da Participação da Indústria Mineral. Internext, 15(3), 80-102. doi:http://dx.doi.org/10.18568/internext.v15i3.583 